\title{
BMJ open Health-related quality of life after serious occupational injury in Egyptian workers: a cross-sectional study
}

\author{
Waleed Salah Eldin, ${ }^{1}$ Jon Mark Hirshon, ${ }^{2,3}$ Gordon S Smith, ${ }^{3}$ \\ Abdel-Aziz Mohamad Kamal, ${ }^{1}$ Aisha Abou-El-Fetouh, ${ }^{1}$ Maged El-Setouhy ${ }^{1}$
}

To cite: Salah Eldin W, Hirshon JM, Smith GS, et al. Health-related quality of life after serious occupational injury in Egyptian workers: a cross-sectional study. BMJ Open 2012;2:e000413. doi:10.1136/bmjopen-2011000413

- Prepublication history and additional data for this paper are available online. To view these files please visit the journal online (http://dx.doi. org/10.1136/bmjopen-2011000413)

Received 8 May 2012 Accepted 15 October 2012

This final article is available for use under the terms of the Creative Commons Attribution Non-Commercial 2.0 Licence; see http://bmjopen.bmj.com

For numbered affiliations see end of article.

Correspondence to Dr Waleed Salah Eldin; waleedsalah3333@ yahoo.com

\section{ABSTRACT}

Objectives: Occupational injuries can have severe socioeconomic consequences; however, little research has examined the health-related quality of life (HRQoL) of workers following occupational injuries, especially in developing countries. This study was to employ the European Quality of Life Five Dimensions (EQ-5D) tool to measure HRQoL 6 months following serious occupational injury sustained by insured workers in the East Delta Region of Egypt.

Design: This cross-sectional study was conducted from July to December 2008 among workers injured severely enough to be off work for at least 6 months after an occupational injury.

Setting: The Nile Insurance Hospital in Qalyubia, Egypt. Participants: Adult workers returning for follow-up evaluation after being given 6 months off work by a physician for an occupational injury.

Outcomes: The workers described their health and quality of life using the EQ-5D instrument.

Results: Most study participants were male $(n=118$ $(90 \%))$, with mean age of 41.5 years. Fractures were the most common type of injury $(n=96(73 \%))$, mostly involving the lower limbs $(n=70(53 \%))$. Participants identified persistent problems related to mobility ( $n=78$ $(60 \%))$, self-care $(n=69(53 \%))$, performing usual activities $(n=109(83 \%))$, pain/discomfort $(n=119(91 \%))$ and anxiety/depression $(n=51(40 \%))$. The perceived HRQoL estimated by the mean $( \pm \mathrm{SD})$ visual analogue scale (VAS) score among injured workers was $61.6 \pm 17.9$. Multivariate linear regression showed an association between poor VAS score and amputations, mobility limitation, self-care problems, pain/discomfort and anxiety/depression.

Conclusions: Some people with occupational injuries experience significant problems such as pain/discomfort, functional limitations and anxiety/depression, long after the injury. Improvement in pain management strategies and physical and psychological rehabilitation may improve their health-related quality of life.

\section{INTRODUCTION}

Work-related injuries constitute an important public health problem because they affect large numbers of workers, especially young people at productive ages. They can be

\section{ARTICLE SUMMARY}

Article focus

- Measurement of health-related quality of life (HRQoL) 6 months following serious occupational injury sustained by insured workers in the East Delta Region of Egypt.

- Determining factors influencing the HRQoL of injured workers.

\section{Key messages}

- Some occupationally injured workers still experience significant problems, such as pain or discomfort, functional limitations and anxiety/ depression even 6 months postserious injury.

- Improvement in pain management, physical and psychological rehabilitation after injury may improve the HRQoL of injured workers.

Strengths and limitations of this study

- Use of standardised questionnaire (European Quality of Life Five Dimensions, EQ-5D) specific for measuring HRQoL.

- Follow-up of all eligible subjects 6 months postinjury.

- Lack of access to preinjury quality-of-life measures for our study group.

- The absence of a measure of the anatomic severity of an injury (injury severity scoring) in the hospital records.

disabling, leading to major adverse social and economic consequences for the worker and his or her family. ${ }^{1}$ These consequences can lead to deterioration in the health-related quality of life (HRQoL). HRQoL has a variety of domains, but generally it includes 'the dimensions of physical functioning, social functioning, role functioning, mental health, and general health perceptions'. ${ }^{2}$ In other words, HRQoL refers to a person's or group's perceived physical and mental health over time. $^{3}$

HRQoL is an important outcome measure in people with serious injuries, ${ }^{4}$ since they do not always return to their preinjury roles and activities. $^{5-7}$ Richmond et $a l^{8}{ }^{8}$ in the USA, 
and Aitken et $a l^{9}{ }^{9}$ in Australia, documented that, at 3-month follow-up after hospital discharge, people who had sustained injury reported poorer health and functioning compared with population norms; similar observations were made by Holtslag and co-workers, ${ }^{4}$ in the Netherlands, based on a survey conducted on 15 months hospitalisation. In a study of people who had experienced lower-extremity injuries, Holtslag et $a l^{10}$ found that half of them had physical limitations related to daily activities and mobility and $60 \%$ were not able to walk 3 months after injury. In other research, injured patients experienced a decrease in physical strength and notable fatigue when performing physical activity, ${ }^{11}$ which probably affected their ability to return to work. ${ }^{5}{ }^{12}$ Long-term effects, both physical and psychological, are common after minor injuries. ${ }^{13}$ Research has focused on the relationships between injury and the risk of post-traumatic stress syndrome. ${ }^{14}$ However, there has been very little investigation into the extent to which work-related injuries affect the HRQoL of individuals, especially in developing countries such as Egypt. ${ }^{15}$

Many factors are known to affect HRQoL after injury, but predictors of diminished HRQoL remain incompletely understood. ${ }^{16}$ Some investigators have concluded that the Injury Severity Scale (ISS) score ${ }^{917}$ and age ${ }^{49}$ are independent predictors of HRQoL, but study results regarding the ISS score are inconsistent. ${ }^{18}$ In one qualitative study of recovery after injury, recovery was complex and did not conform to the views of most clinicians, ${ }^{19}$ underscoring the importance of understanding patient's perspective with regard to the broader aftermath of injuries.

This purpose of the study described in this article was to use the European Quality of Life Five Dimensions tool to measure HRQoL 6-month following serious occupational injury in insured workers in the East Delta Region of Egypt. ${ }^{20}$

\section{METHODOLOGY}

\section{Study design, setting and sample}

This hospital-based cross-sectional study was conducted in the Nile Insurance Hospital, the primary medical facility responsible for treating medically insured workers working in the Qalyubia governorate of Egypt. Egyptian law requires that all workers be covered by an insurance policy. During the study period (JulyDecember 2008), the number of people presenting to the Nile Insurance Hospital with work-related injuries totalled 2129. Our study population was the subset of patients injured severely enough to require at least 6 months away from work.

Egyptian workers' compensation insurance policy stipulates that all injured workers who have been off work for 6 months must be evaluated at the 6-month mark at one of the governorates (counties) insurance hospitals. The results of this evaluation are used to determine the patient's ability to return to work and the payment of benefits. The need for additional time off from work was determined by a committee, based on the results of the follow-up visit; the committee did not have access to the HRQoL data collected for research purposes. Study participants worked in various industrial jobs in the East Delta Region. Patients were recruited for the study by a physician working in the Nile Insurance Hospital, who was trained to administer the research instrument.

Sample size was calculated using the statistical package software program STATAV.11, setting the type-1 error $(\alpha)$ at 0.05 and the power $(1-\beta)$ at 0.8 . Results from a study of intensive care unit (ICU) patients ${ }^{21}$ showed that more than three-fourths of injured patients experienced pain/ discomfort 6 months after injury. For our study, we assumed that $88 \%$ of injured workers would be experiencing pain/discomfort 6 months after injury. Calculation according to these values produced a minimal sample size of 118 cases. We expected to recruit 131 patients between 1 July and 31 December 2008. This sample size has enough power (98\%) to assess differences in VAS scores between patients with and without anxiety/depression manifestations for statistical significance.

\section{Study tools}

The interview questionnaire completed by participants had three sections: (1) sociodemographic background (age, sex, education, residence and marital status), (2) details about current injury (type of injury and injured body part) and (3) HRQoL, as by the European Quality of Life Five Dimensions (EQ-5D).$^{22}$ The questionnaire was developed in English, reviewed by coauthors of this paper and then translated into Arabic by the first author. The English version of the EQ-5D was also translated into Arabic. A senior faculty member at the university who has an excellent command of English reviewed and approved the translation, giving particular attention to ensuring the integrity of the EQ-5D questions. The questionnaire was tested in a pilot study and validated prior to implementation.

The EQ-5D is a brief, standardised, generic measure of HRQoL that provides a profile of patient's function and a global health state rating. ${ }^{20}$ The EQ-5D allows (1) assessment of an individual's physical, social and psychological status, (2) measurement of HRQoL from the individual's subjective view and (3) identification of possible predictors of diminished HRQoL in specific individuals and groups. This information can be used to guide the management of patients who have sustained occupational injuries. The EQ-5D was developed by the EuroQoL Group, an international research network established in 1987 by investigators from Finland, the Netherlands, Sweden and the UK. It defines health in terms of five dimensions: mobility, self-care, usual activities (work, study, housework, family and leisure), pain or discomfort and anxiety or depression. Each dimension is subdivided into three categories, which indicate whether the respondent has no problem, a moderate problem or an extreme problem. ${ }^{23}$ The instrument 
generates a global rating of current health using a VAS, with scores ranging from 0 (worst imaginable) to 100 (best imaginable). ${ }^{24}$

The EQ-5D comprises two pages: on the first page, respondents record the extent of their problem in each of the five dimensions, and on the second page, they record their perception of their overall health on a VAS. ${ }^{23}$ Patients were asked to complete both sections. The self-rated HRQoL was collected from injured workers by asking them to report their current HRQoL after injury. The mean VAS score was calculated and compared according with different variables. Approval for the use of the copyrighted instrument was obtained from the EuroQol Executive Office.

\section{Data management and analysis}

The collected data were coded, entered into Microsoft Access and analysed with SPSS V.15.0.1 (SPSS Inc, Chicago, Illinois, USA). An independent sample t test was used to compare patients with and without a specific problem in relation to the VAS score. Analysis of variance was used to compare VAS scores between three or more groups of patients, that is, patients with different

\begin{tabular}{|c|c|c|}
\hline \multirow[b]{2}{*}{ Demographics and injury profile } & \multicolumn{2}{|c|}{ Total $(\mathrm{N}=131)$} \\
\hline & $\bar{n}$ & $\%$ \\
\hline \multicolumn{3}{|l|}{ Gender } \\
\hline Male & 118 & 90.1 \\
\hline Female & 13 & 9.8 \\
\hline \multicolumn{3}{|l|}{ Education level } \\
\hline Illiterate & 26 & 19.8 \\
\hline Read and write & 16 & 12.2 \\
\hline Primary education & 17 & 13 \\
\hline Preparatory education & 10 & 7.6 \\
\hline Secondary education & 42 & 32.1 \\
\hline Institute/university & 20 & 15.3 \\
\hline \multicolumn{3}{|l|}{ Residency } \\
\hline Rural & 73 & 55.7 \\
\hline Urban & 58 & 44.3 \\
\hline \multicolumn{3}{|l|}{ Marital status } \\
\hline Single & 16 & 12.2 \\
\hline Married & 115 & 87.8 \\
\hline \multicolumn{3}{|l|}{ Type of injury } \\
\hline Fracture & 96 & 73.3 \\
\hline Amputation & 15 & 11.5 \\
\hline Cut & 7 & 5.3 \\
\hline Foreign body & 7 & 5.3 \\
\hline Wound & 2 & 1.5 \\
\hline Tear & 2 & 1.5 \\
\hline Burn & 2 & 1.5 \\
\hline \multicolumn{3}{|l|}{ Injured part } \\
\hline Head/neck & 7 & 5.3 \\
\hline Upper limb & 44 & 33.6 \\
\hline Trunk & 10 & 7.6 \\
\hline Lower limb & 70 & 53.4 \\
\hline
\end{tabular}

types of injury in relation to the VAS score. Pearson correlation was used to look for a linear relation between age and VAS score. Multiple linear regression analysis was used to investigate the collective influence of background variables (independent variables), using the VAS score as the dependent variable. Independent variables were selected based on their relationship with the VAS score in a univariate analysis. Age, gender, marital status, education, type of injury, injured body part and the EQ-5D health dimensions were included in the model as independent variables.

\section{Ethical considerations}

Institutional review board approval was obtained from the University of Maryland School of Medicine, Ain Shams University and the Egyptian Ministry of Health and Population. Informed consent form was obtained from study participants. All data were de-identified and kept confidential.

\section{RESULTS}

During the 6-month study period, 131 individuals returned to the hospital for their 6-month postinjury evaluation. All agreed to participate in the study. Most subjects were males $(\mathrm{n}=118(90.1 \%))$ and married $(\mathrm{n}=115(87.1 \%))$, with a mean age of 40.1 years (range, 18-60 years). The main types of injury (the most severe, based on chart review by the lead author) among the study participants were fracture $(\mathrm{n}=96(73.3 \%))$ and amputation $(\mathrm{n}=15 \quad(11.5 \%))$. The most frequently

Table 2 Number of respondents reporting a problem in each European Quality of Life Five Dimensions (EQ-5D)*

\begin{tabular}{lcc} 
& \multicolumn{2}{c}{ Total (N=131) } \\
\cline { 2 - 3 } & $\mathbf{n}$ & $\%$ \\
\hline Mobility & 53 & \\
$\quad$ No problems & 78 & 40.5 \\
Some problems & 0 & 59.5 \\
Confined to bed & & 0 \\
Self-care & 62 & \\
$\quad$ No problems & 69 & 47.3 \\
Some problems & 0 & 52.7 \\
Extreme problem & & 0 \\
Usual activities & 22 & \\
$\quad$ No problems & 109 & 16.8 \\
Some problems & 0 & 83.2 \\
Extreme problem & & 0 \\
Pain/discomfort & 12 & 9.2 \\
$\quad$ None & 119 & 90.8 \\
Moderate & 0 & 0 \\
Extreme & & \\
Anxiety/depression & 80 & 61.1 \\
None & 51 & 39.9 \\
Moderate & 0 & \\
Extreme & & \\
*Mean EQ-5D visual analogue scale score: $61.6 \pm 17.9$. & \\
& &
\end{tabular}


injured body part was the lower limbs $(n=70(53.4 \%))$, followed by the upper limbs $(n=44(33.6 \%))$ (table 1$)$. More than half of respondents $(n=78(59.5 \%))$ reported problems with mobility (table 2). Ninety-one per cent $(n=119)$ of participants reported moderate pain or discomfort, and $40 \%$ reported moderate anxiety or depression. The mean EQ-5D VAS score (participants' self-rating of their current own health state) was 61.6, with a SD of 17.9) out of a possible maximum of 100.

The mean VAS score did not differ significantly in relation to gender, residence, educational level or marital status (data not shown). Also, there was no significant correlation between age and VAS score. The mean VAS score showed a highly statistically significant difference in relation to mobility, self-care activities, usual activities (work, study, housework, family and leisure), pain/discomfort and anxiety/depression. Patients who had problems in any of the health domains listed above had a lower mean VAS score than those with no problems. However, the mean VAS scores were

\begin{tabular}{|c|c|c|c|c|c|}
\hline & \multirow[b]{2}{*}{$\mathbf{N}$} & \multicolumn{2}{|c|}{ VAS score } & \multirow[b]{2}{*}{$t / F$} & \multirow{2}{*}{$\begin{array}{l}\mathbf{p} \\
\text { Value }\end{array}$} \\
\hline & & Mean & SD & & \\
\hline \multicolumn{6}{|l|}{ Mobility } \\
\hline No problems & 53 & 71.8 & 18.40 & $5.8^{*}$ & 0.0001 \\
\hline $\begin{array}{l}\text { Some problems } \\
\text { Self-care }\end{array}$ & 78 & 54.61 & 13.83 & & \\
\hline No problems & 62 & 70.64 & 16.3 & $6.28^{*}$ & 0.0001 \\
\hline $\begin{array}{l}\text { Some problems } \\
\text { Usual activity }\end{array}$ & 69 & 53.47 & 15.22 & & \\
\hline No problems & 22 & 80 & 18.51 & $5.93^{*}$ & 0.0001 \\
\hline $\begin{array}{l}\text { Some problems } \\
\text { Anxiety/ } \\
\text { depression }\end{array}$ & 109 & 57.88 & 15.4 & & \\
\hline $\begin{array}{l}\text { No anxiety/ } \\
\text { depression }\end{array}$ & 80 & 66.25 & 18.7 & $4.19^{\star}$ & 0.0001 \\
\hline $\begin{array}{l}\text { Moderate anxiety/ } \\
\text { depression }\end{array}$ & 51 & 54.31 & 13.74 & & \\
\hline \multicolumn{6}{|l|}{ Pain/discomfort } \\
\hline $\begin{array}{l}\text { No pain/ } \\
\text { discomfort }\end{array}$ & 12 & 83.33 & 19.6 & $4.75^{\star}$ & 0.0001 \\
\hline $\begin{array}{l}\text { Moderate pain/ } \\
\text { discomfort } \\
\text { Injured body part }\end{array}$ & 119 & 59.41 & 16.2 & & \\
\hline Head or neck & 7 & 57.14 & 19.7 & $1.71 \dagger$ & 0.167 \\
\hline Upper limb & 44 & 66.13 & 16.31 & & \\
\hline Trunk & 10 & 55 & 15.81 & & \\
\hline Lower limb & 70 & 60.14 & 18.68 & & \\
\hline \multicolumn{6}{|l|}{ Type of injury } \\
\hline $\begin{array}{l}\text { Cuts/wound/tear/ } \\
\text { foreign body }\end{array}$ & 18 & 63.8 & 18.83 & $0.222 \dagger$ & 0.801 \\
\hline Fractures/burn & 98 & 61.02 & 17.08 & & \\
\hline Amputation & 15 & 62.66 & 22.82 & & \\
\hline
\end{tabular}

significantly different when injured body part or types of injury were compared among three groups: workers with wounds, cuts, tears, or foreign body; those with fractures and burns; and those who sustained amputation (table 3).

Multiple linear regression analysis was used to investigate the collective influence of background variables, using the VAS score as the dependent variable (table 4). Multivariate modelling suggested several independent risk factors for poorer HRQoL. After adjustment for these factors, significant risk factors for a lower score included amputation versus other type of injuries $(\mathrm{p}<0.05)$, mobility limitation $(\mathrm{p}<0.001)$, self-care activities $(\mathrm{p}<0.001)$, pain/discomfort $(\mathrm{p}<0.01)$ and anxiety/ depression $(\mathrm{p}<0.05)$. This model accounted for $54.1 \%$ of the common variance in the VAS score $(\mathrm{F}=9.04$, $\mathrm{df}=130, \mathrm{p}<0.01)$.

Table 4 Multivariate regression model describing the relation between perceived health-related quality of life (visual analogue scale (VAS) score)

\begin{tabular}{|c|c|c|c|c|}
\hline & & & $95 \% \mathrm{Cl}$ fc & \\
\hline & $\boldsymbol{\beta}$ & $\begin{array}{l}\mathbf{p} \\
\text { Value }\end{array}$ & $\begin{array}{l}\text { Lower } \\
\text { bound }\end{array}$ & $\begin{array}{l}\text { Upper } \\
\text { bound }\end{array}$ \\
\hline Age & -0.064 & 0.586 & -0.296 & 0.168 \\
\hline Sex (female) & 1.290 & 0.762 & -7.116 & 9.695 \\
\hline $\begin{array}{l}\text { Residence } \\
\text { (urban) }\end{array}$ & -1.717 & 0.491 & -6.643 & 3.210 \\
\hline Education† & & & & \\
\hline $\begin{array}{c}\text { Read and } \\
\text { write/primary }\end{array}$ & 3.798 & 0.294 & -3.334 & 10.929 \\
\hline Preparatory & 0.256 & 0.961 & -10.147 & 10.658 \\
\hline Secondary & 4.977 & 0.169 & -2.154 & 12.108 \\
\hline $\begin{array}{l}\text { High } \\
\text { education }\end{array}$ & 0.175 & 0.968 & -8.390 & 8.741 \\
\hline $\begin{array}{l}\text { Marital status } \\
\text { (married) }\end{array}$ & 3.404 & 0.388 & -4.370 & 11.177 \\
\hline Injury typeł & & & & \\
\hline $\begin{array}{l}\text { Fracture/ } \\
\text { burn }\end{array}$ & -4.537 & 0.226 & -11.921 & 2.847 \\
\hline Amputation & -10.946 & $0.040 \ddagger$ & -21.393 & -0.499 \\
\hline Injury location§ & & & & \\
\hline Upper limb & 5.326 & 0.405 & -7.308 & 17.959 \\
\hline Trunk & 6.280 & 0.377 & -7.737 & 20.296 \\
\hline Lower limb & 9.193 & 0.128 & -2.675 & 21.062 \\
\hline Mobility ability & -16.545 & $0.001^{\star *}$ & -24.335 & -8.755 \\
\hline $\begin{array}{l}\text { Self-care } \\
\text { activities }\end{array}$ & -12.042 & $0.001^{\star *}$ & -17.069 & -7.016 \\
\hline $\begin{array}{l}\text { Usual activity } \\
\text { affected }\end{array}$ & -2.879 & 0.502 & -11.338 & 5.580 \\
\hline $\begin{array}{l}\text { Anxiety/ } \\
\text { depression }\end{array}$ & -5.331 & $0.036^{*}$ & -10.312 & -0.350 \\
\hline $\begin{array}{l}\text { Pain/ } \\
\text { discomfort }\end{array}$ & -13.446 & $0.005^{\star \star}$ & -22.655 & -4.237 \\
\hline $\begin{array}{l}{ }^{*} \text { Significant }(p<0 \\
{ }^{*}{ }^{*} \text { Highly significa } \\
\text { †Reference grou } \\
\text { †Reference grou } \\
\text { §Reference grou }\end{array}$ & $\begin{array}{l}\text { ( } p<0.01) \\
\text { illiterate wa } \\
\text { wound, cut, } \\
\text { head or ne }\end{array}$ & $\begin{array}{l}\text { tear, or } f \\
\text { k injury. }\end{array}$ & eign bod & ies. \\
\hline
\end{tabular}




\section{DISCUSSION}

This study provides the first data on the impact of serious occupational injury on the HRQoL of Egyptian workers. The EQ-5D was the instrument of choice because it is simple and short and has acceptable reliability. ${ }^{22}$ The questionnaire permitted estimation of an overall quality-of-life index and specifically measured a range of physical and non-physical dimensions. ${ }^{25}$

In terms of health problems experienced by study participants 6 months after injury, the findings indicate that the majority had moderate levels of pain or discomfort $(90.8 \%)$, difficulty performing usual activities (83.2\%), mobility problems $(59.5 \%)$ or limitations in self-care $(52.7 \%)$, reflecting the multifaceted impact of occupational injury. Anxiety or depression was reported by approximately $40 \%$ of respondents reporting moderate. Untreated anxiety or depression can impede recovery and work performance and delay return to work. ${ }^{21} 26$

Our findings are consistent with those of a Swedish study of quality of life 5 years after major trauma, in which $68 \%$ of patients reported considerable physical disability and $41 \%$ described psychological issues. ${ }^{6}$ Granja et $a l^{27}$ reported that as many as $78 \%$ of patients were experiencing pain/discomfort 6 months after injury. A study based at a level I trauma centre in the Netherlands found a $58 \%$ incidence of pain/discomfort 1 year after major trauma. ${ }^{28}$ In a follow-up study, conducted $2-7$ years after trauma, $58 \%$ of patients still experienced pain/discomfort and $15 \%$ had problems with self-care. ${ }^{29}$ Our study revealed those problems in much higher percentages of patients; the difference might be explained by the time of inquiry -6 months after injury in our study and 2-7 years after injury in the Dutch evaluation. None of the published studies on this topic involved a population directly comparable to ours.

Persistent pain is a problem revealed by many studies of injured workers. This demonstrates that pain management in the acute and subacute phases of trauma care is clearly important. Improved pain management for trauma patients not only increases comfort and reduces suffering but also reduces morbidity and improves longterm outcomes. ${ }^{30} 31$ The problems described by our study participants were primarily moderate, in agreement with the findings of the 2-yesr to 7-year follow-up study. ${ }^{29}$

We do not know preinjury EQ-5D scores for our study population or have access to suitable population norms for Egypt, but we can surmise that the values are much higher than would be expected for an uninjured population. The 2004 report of the EuroQol Group's International Task Force on Self-Reported Health provides number for comparison. EQ-5D data from the 15 countries represented on that task force indicate the following percentages in the 40-year to 59-year age group reporting problems in the indicated categories: mobility, $15 \%$; self-care, $3 \%$; usual activities, $15 \%$; pain/discomfort, $42 \%$ and anxiety/depression, $29 \% .^{32}$ The percentages in the 18-year to 39-year group were much lower.
The injured workers in our study (with a median age of 40 years) reported much higher levels of problems across all dimensions.

The mean VAS score of our study participants, 6 months after injury, was $61.6 \pm 17.9$. Holtslag et al documented a mean score of $73.5 \pm 17.8$ among trauma patients 3 months after injury. ${ }^{31}$ Our patients' VAS scores did not show significant difference with regard to age, gender, educational level, marital status, injured body part or type of injury. Our results are partially consistent with those of a Dutch study, in which univariate analyses revealed non-significant differences in EQ-5D VAS scores with regard to sex and injury location but significant differences with regard to age and education level. ${ }^{33}$ In other studies, the relationship between age and HRQoL after trauma is uncertain, although older patients have been reported to experience the greatest impairment. ${ }^{634}$

When evaluating the possible determinants of HRQoL denoted by VAS score after injury, background variables have to be considered. For example, a person's perceived state of health is influenced by the presence of illness or disability as well as socioeconomic factors. ${ }^{35}$

Adjusting for age, sex, residence, marital status, educational level in a multivariate analysis, we found amputations, mobility limitation, pain/discomfort, depression/ anxiety, impairment of self-care activities and education level were significant determinants of poorer HRQoL. The injured body part and the impairment in the performance of usual activities were not significant in the model. This finding about site of injury is consistent with results of a previous study that found no significant difference in quality of life between patients with or without severe head injury 2 years after discharge from an ICU. ${ }^{33}$ One would expect that patients with severe head injury would have the lowest quality of life. However, patients with severe head injury have reported not only equal but even better quality of life than patients with injuries to other body parts. ${ }^{29}$

Our regression model indicated that amputation was a significant determinant of poorer VAS score, consistent with the findings of Gustafsson and Ahlström, ${ }^{36}$ who reported that patients with amputations more often experienced a worse life situation. They also found that white-collar workers reported fewer functional limitations and a better life situation than bluecollar workers. Our workers tended to be blue-collar workers, which could explain the low rating of their health status.

In a Dutch study, multivariate linear regression analysis was used to explore the relation between sociodemographic factors, physical factors and injury location with the ISS score and the EQ-5D VAS score on the other. Injury site (spinal cord, lower extremity or brain), education level and comorbidity were significantly associated with poorer EQ-5D VAS score, while age, gender and ISS score did not have independent effects on the long-term functional consequences of major trauma as measured with the EQ-5D. ${ }^{32}$ 


\section{LIMITATIONS}

The limitations of this study include the absence of a measure of the anatomic severity of an injury (injury severity scoring) in the hospital records; access to this information would facilitate comparisons with other studies. However, all our patients had been injured severely enough to require at least 6 months away from work. In addition, we did not have access to preinjury quality-of-life measures for our study group. All study participants had been employed in the formal work sector, indicated by their workers compensation coverage; therefore, we can only assume that they relatively had few physical and psychological problems before being injured. Unfortunately, population norms for Egypt are not included in the 2004 EQ-5D report and none are listed for a comparable population on the EuroQol website (but there is increasing interest in HRQoL measures in the Arab world). ${ }^{32} 37$ While there was no official Egyptian Arabic translation of the EQ-5D available at the time of our study, we took care to ensure the meaning of the EQ-5D questions.

Our findings are limited to workers with occupational injuries requiring at least a 6-month leave of absence. Employees with injuries of this severity are required to return to the hospital for re-evaluation. This requirement might have influenced participants' responses on our questionnaires if they suspected that their answers could influence the committee charged with deciding if they were able to return to work. We were careful to explain that the EQ-5D assessment was separate from the return-to-work evaluation and that the responses would be kept confidential and would not be used for treatment decisions.

Finally, this work was conducted in a middle-income Arab country; therefore, cultural circumstances might have influenced participants' self-perceived quality of life. The characteristics of the population from which our study group was drawn could limit the generalisability of our findings beyond this setting.

\section{CONCLUSIONS}

Some people who sustain occupational injuries experience significant problems, such as pain/discomfort, functional limitations and anxiety/depression, long after the injury. Factors such as mobility challenges may allow identification of injured workers with poor HRQoL so that appropriate care and rehabilitation services can be directed to them. The clinical care of patients with occupational injuries should include not only surgical or medical treatment at the time of injury but also follow-up for pain management as well as physical and psychological rehabilitation.

\author{
Author affiliations \\ ${ }^{1}$ Community, Environmental and Occupational Medicine Department, Ain \\ Shams University, Cairo, Egypt \\ ${ }^{2}$ Department of Emergency Medicine, University of Maryland School of \\ Medicine, Baltimore, Maryland, USA
}

${ }^{3}$ Charles McMathias, Jr., National Study Center for Trauma and Emergency Medical Systems, of the Shock, Trauma, and Anesthesia Research Center, University of Maryland School of Medicine, Baltimore, Maryland, USA

Acknowledgements The authors acknowledge Linda J Kesselring, MS, ELS, Department of Emergency Medicine, University of Maryland School of Medicine, for her assistance in copyediting the manuscript.

Contributors JMH contributed to study design, data analysis, review of results and manuscript development. ME-S is the main supervisor of the PhD thesis out of which this manuscript was developed. He contributed in developing the study objectives, study design, data analysis, reviewing the results and manuscript development. GS contributed to study design, data analysis, review of results and manuscript development, review the final document, as there were inconsistent usage of terms (such as HRQOL versus $\mathrm{HRQoL}$ ) as well as minor English issues. AA-E-F is the supervisor of the PhD thesis out of which this manuscript was developed. She contributed in developing the study objectives, study design, data analysis, reviewing the results and manuscript development. A-AMK is the supervisor of the $\mathrm{PhD}$ thesis out of which this manuscript was developed. He contributed in developing the study objectives, study design, data analysis, reviewing the results and manuscript development.

Funding This work was supported by the US National Institutes of Health Fogarty International Center Fogarty Grant 5D43TW007296. GS was supported by a grant from the US National Institute on Alcohol Abuse and Alcoholism (R01AA18707).

Competing interests None.

Patient consent Obtained.

Ethics approval Institutional Review Board approval was obtained from University of Maryland School of Medicine, Ain Shams University and the Egyptian Ministry of Health and Population.

Provenance and peer review Not commissioned; externally peer reviewed. Data sharing statement No additional data are available.

\section{REFERENCES}

1. Nagai $R$, Lefèvre AMC, Lefèvre $F$, et al. Knowledge and practices by adolescents in preventing occupational injuries: a qualitative study. Rev Saúde Pública 2007;41:404-11.

2. Wilson IB, Cleary PD. Linking clinical variables with health-related quality of life: a conceptual model of patient outcomes. JAMA 1995;273:59-65.

3. Centers for Disease Control and Prevention. Health-related quality of life. www.cdc.gov/hrqol/ (accessed on 19 Sep 2012).

4. Holtslag HR, Post MW, Lindeman E, et al. Long-term functional health status of severely injured patients. Injury 2007;38:280-9.

5. DePalma JA, Fedorka P, Simko LC. Quality of life experienced by severely injured trauma survivors. AACN Clin Issues 2003;14:54-63.

6. Sluys K, Haggmark T, Iselius L. Outcome and quality of life 5 years after major trauma. J Trauma 2005;59:223-32.

7. Richmond TS, Kauder D, Hinkle J, et al. Early predictors of long-term disability after injury. Am J Crit Care 2003;12:197-205.

8. Richmond TS, Thompson HJ, Kauder D, et al. A feasibility study of methodological issues and short-term outcomes in seriously injured older adults. Am J Crit Care 2006;15:158-65.

9. Aitken LM, Davey T, Ambrose J, et al. Health outcomes of adults 3 months after injury. Injury 2007;38:19-26.

10. Holtslag HR, Buskens E, Rommers C, et al. Long-term outcome after lower extremity injuries in severely injured patients. Eur $J$ Trauma 2006;4:365-73.

11. Haukeland JV. Welfare consequences of injuries due to traffic accidents. Accid Anal Prev 1996;28:63-72.

12. Halcomb E, Daly J, Davidson $P$, et al. Life beyond severe traumatic injury: an integrative review of the literature. Aust Crit Care 2005;18:17-23.

13. Mayou R, Bryant B. Consequences of road traffic accidents for different types of road user. Injury 2003;34:197-202.

14. Holbrook T, Hoyt $D$, Coimbra R, et al. Long-term posttraumatic stress disorder persists after major trauma in adolescents: new data on risk factors and functional outcome. J Trauma 2005;58:769-71. 
15. Franzen C, Christine BC, Hans S, et al. Injured road users' health-related quality of life after telephone intervention: a randomized controlled trial. J Clin Nurs 2008;18:108-16.

16. Kiely JM, Brasel KJ, Weidner KL, et al. Predicting quality of life six months after traumatic injury. J Trauma 2006;61:791-8.

17. Dimopoulou I, Anthi A, Mastora Z, et al. Health-related quality of life and disability in survivors of multiple trauma one year after intensive care unit discharge. Am J Phys Med Rehabil 2004;83: $171-6$.

18. Richmond TS, Kauder D, Schwab CS. A prospective study of predictors of disability at 3 months following non-central nervous system trauma. $J$ Trauma 1998;44:635-43.

19. Richmond TS, Thompson HJ, Deatrick JA, et al. Journey towards recovery following physical trauma. J Adv Nurs 2000;32:1341-7.

20. Brooks $\mathrm{R}$, Rabin $\mathrm{R}$, de Charro $\mathrm{F}$. The measurement and valuation of health status using EQ-5D: a European perspective: evidence from the EuroQol BIO MED Research Program. Rotterdam: Kluwer Academic Publishers, 2003.

21. Kessler RC, Merikangas KR, Wang PS. The prevalence and correlates of workplace depression in the national comorbidity survey replication. J Occup Environ Med 2008;50:381-90.

22. Rabin R, de Charro F. EQ-5D: a measure of health status from the EuroQol Group. Ann Med 2001;33:337-43.

23. Kind P, Dolan P, Gudex C, et al. Variations in population health status: results from a United Kingdom national questionnaire survey. BMJ 1998;316:736-41.

24. Mathews WC, May S. EuroQol (EQ-5D) measure of quality of life predicts mortality, emergency department utilization, and hospital discharge rates in HIV-infected adults under care. Health Qual Life Outcomes 2007;5:5.

25. Needham DM, Dowdy DW, Mendez-Tellez PA, et al. Studying outcomes of intensive care unit survivors: measuring exposures and outcomes. Intensive Care Med 2005;31:1153-60.

26. Lagerveld SE, Blonk RW, Brenninkmeijer V, et al. Work-focused treatment of common mental disorders and return to work: a comparative outcome study. J Occup Health Psychol 2012;17:220-34.

27. Granja C, Teixeira-Pinto A, Costa-Pereira A. Quality of life after intensive care-evaluation with EQ-5D questionnaire. Intensive Care Med 2002;28:898-907.

28. Vles WJ, Steyerberg EW, Essink-Bot ML. Prevalence and determinants of disabilities and return to work after major trauma. $J$ Trauma 2005;58:126-35.

29. Ulvik A, KvaLe R, Wentzel-Larsen T, et al. Quality of life 2-7 years after major trauma. Acta Anaesthesiol Scand 2008;52:195-201.

30. Davidson EM, Ginosar Y, Avidan A. Pain management and regional anaesthesia in the trauma patient. Curr Opin Anaesthesiol 2005;18:169-74.

31. Cohen SP, Christo PJ, Moroz L. Pain management in trauma patients. Am J Phys Med Rehabil 2004;83:142-61.

32. Szende A, Williams A, eds. Measuring self-reported population health: an international perspective based on EQ-5D. www.euroqol. org/eq-5d/population-norms.html (accessed 19 Sept 2012).

33. Holtslag HR, van Beeck EdF, Lindeman E, et al. Determinants of long-term functional consequences after major trauma. J Trauma 2007;62:919-27.

34. Vazquez MG, Rivera FR, Perez AA. Analysis of quality of life in poly traumatized patients two years after discharge from an intensive care unit. J Trauma 1996;41:326-32.

35. Jelsma J, Ferguson G. The determinants of self-reported health-related quality of life in a culturally and socially diverse South African community. Bull World Health Organ 2004;82:206-12.

36. Gustafsson M, Ahlström G. Problems experienced during the first year of an acute traumatic hand injury-a prospective study. $J$ Clin Nurs 2004;13:986-95.

37. Al Sayah F, Ishaque S, Lau D, et al. Health related quality of life measures in Arabic speaking populations: a systematic review on cross-cultural adaptation and measurement properties. Qual Life Res 2012 Feb 18 (Epub ahead of print) doi: 10.1007/s11136-0120129-3. 